\title{
Japonya'da Tarih Eğitimi ve Toplumsal Bellek Sorunu
}

\section{Hasan Topaçoğlu}

Yeni Medya ve İletişim Bölümü, İletişim Fakültesi, Üsküdar Üniversitesi, İstanbul, Türkiye

Sorumlu Yazar: Hasan Topaçoğlu, hasan.topacoglu@uskudar.edu.tr

Makale Türü: Derleme Makalesi

Kaynak Gösterimi: Topaçoğlu, H. (2021). Japonya'da tarih eğitimi ve toplumsal bellek sorunu. Eğitimde Kuram ve Uygulama, 17(Özel Sayı 1), 11-20. doi: 10.17244/eku.878418

Etik Not: Araştırma ve yayın etiğine uyulmuştur. Bu çalışma, "Derleme Makalesi” olup ayrıca bir etik onay süreci işletilmemiştir.

\section{History Education and Collective Memory Problems in Japan}

\section{Hasan Topaçoğlu}

Department of New Media and Communication, Faculty of Communication, Uskudar University, Istanbul, Turkey

Corresponding Author: Hasan Topaçoğlu, hasan.topacoglu@uskudar.edu.tr

Article Type: Review Article

To Cite This Article: Topaçoğlu, H. (2021). Japonya'da tarih eğitimi ve toplumsal bellek sorunu. Eğitimde Kuram ve Uygulama, 17(Special Issue.1), 11-20. doi: 10.17244/eku.878418

Ethical Note: Research and publication ethics were followed. This study is "Review Article"; hence, no proceed an ethical clearance evaluation. 


\title{
Japonya'da Tarih Eğitimi ve Toplumsal Bellek Sorunu
}

\author{
Hasan Topaçoğlu \\ Yeni Medya ve İletişim Bölümü, İletişim Fakültesi, Üsküdar Üniversitesi, İstanbul, Türkiye
}

ORCID: https://orcid.org/0000-0002-1182-3905

\begin{tabular}{|c|c|}
\hline Öz & Makale Bilgisi \\
\hline 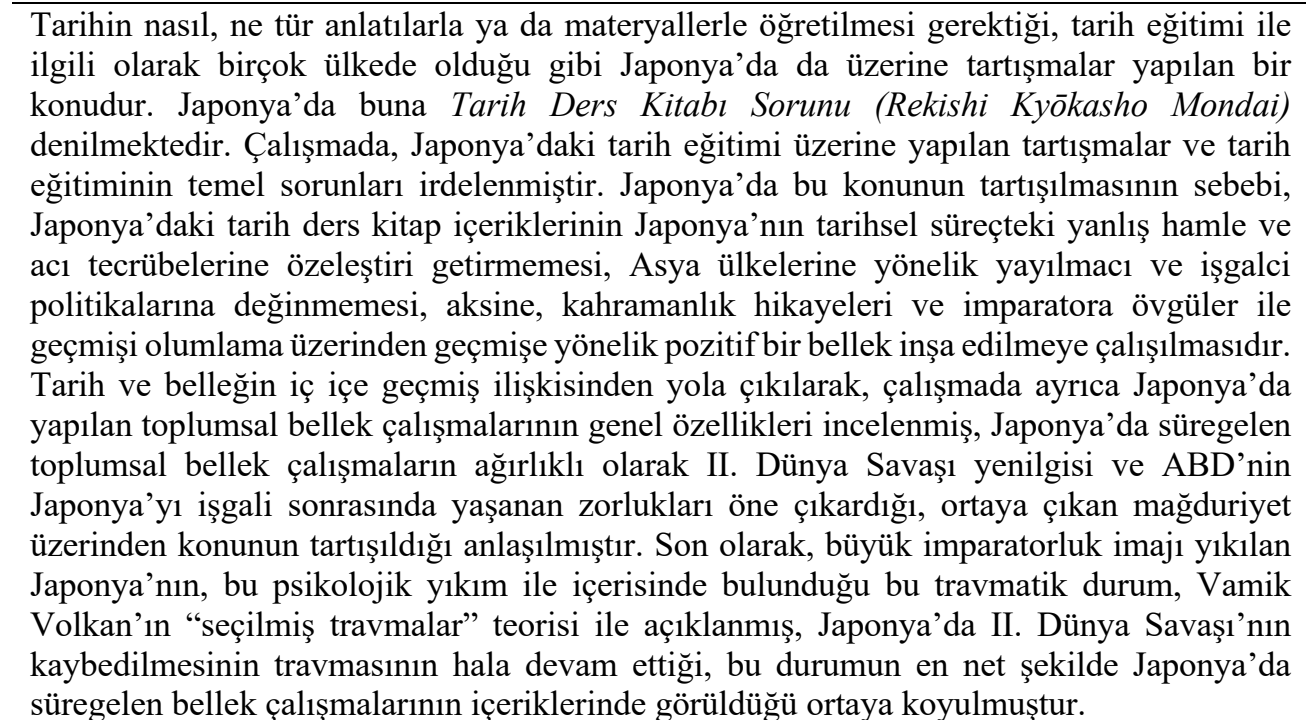 & $\begin{array}{l}\text { Anahtar kelimeler: Japonya, } \\
\text { Seçilmiş travma, Tarih ders } \\
\text { kitabı sorunu, Tarih eğitimi, } \\
\text { Toplumsal bellek } \\
\text { Makale Geçmişi: } \\
\text { Geliş: } 11 \text { Şubat } 2021 \\
\text { Düzeltme: } 5 \text { Nisan } 2021 \\
\text { Kabul: } 16 \text { Haziran } 2021\end{array}$ \\
\hline
\end{tabular}

\section{History Education and Collective Memory Problems in Japan}

\begin{tabular}{|c|c|}
\hline Abstract & Article Info \\
\hline $\begin{array}{l}\text { How history should be taught, with what kind of narratives or materials is an issue that has } \\
\text { been discussed in Japan as in many countries regarding history education. In Japan, this is } \\
\text { called the History Textbook Controversies (Rekishi Kyōkasho Mondai). This study } \\
\text { introduces the discussions on history education in Japan and the general problems of history } \\
\text { education. The reason for the discussion of this issue in Japan is that, for so many years } \\
\text { now, the content of the history textbooks in Japan did not bring enough self-criticism to } \\
\text { Japan's experiences of wrong doings and pain that they caused in the historical process, did } \\
\text { not contain enough regret for its expansionist and invasive policies towards Asian countries. } \\
\text { On the contrary, the history textbooks contained heroic stories and praises to the emperor. } \\
\text { It is explained as an attempt to build a positive memory for the past through affirmation of } \\
\text { the past policies. Based on the intertwined relationship of history and memory, the study } \\
\text { also examined the general characteristics of collective memory studies in Japan. It is } \\
\text { understood that the ongoing memory studies in Japan mainly highlights the difficulties } \\
\text { experienced after the defeat of World War II and the US invasion of Japan and studies } \\
\text { mostly put forward victimization against USA. We also explained this traumatic situation } \\
\text { and psychological destruction in which Japan, whose image of great empire was destroyed, } \\
\text { with the theory of chosen traumas of Vamik Volkan. It is claimed that in Japan, the trauma } \\
\text { of the loss of World War II continues up to day, and the footsteps of this situation can be } \\
\text { seen in the contents of various ongoing memory studies in Japan. }\end{array}$ & $\begin{array}{l}\text { Article History: } \\
\text { Received: } 11 \text { February } 2021 \\
\text { Revised: } 5 \text { April } 2021 \\
\text { Accepted: } 16 \text { June } 2021 \\
\text { Article Type: Review Article }\end{array}$ \\
\hline
\end{tabular}




\section{Extended Summary}

How history should be taught, with what kind of narratives or materials, is a subject of discussion in Japan as well as in many countries regarding history education. In the Introduction part of this study, it is stated that official historical narratives can lead to debates in relation to the different experiences that countries have had both within themselves and with neighbouring countries. One of the countries where such discussions are intense is Japan. These discussions, which are based on the reflections of Japan's official history narrative in history textbooks, also affect the collective memory of Japanese society.

In the Literature Review and Theoretical Explanations part of the study, the concept of history, history research, historian, history education, and its close relationship with memory are explained, based on the changes in concepts and roles over time. In addition to the relationship between the concepts of history and memory, this study introduces Vamik Volkan's theory of chosen trauma, and the discussions on history and memory in Japan are associated with Vamik Volkan's chosen trauma theory. Associating this theory with the problem of history and collective memory in Japan can be considered as a pioneering attempt in the literature in this respect.

In the third part of the study, concrete discussions on history education in Japan are explained. This is called the History Textbook Controversies (Rekishi Kyōkasho Mondai). In this section, the debates on history education in Japan and the main problems of history education are examined. The History Textbook Controversies in Japan is not only a domestic issue but also an international one. It is not surprising to hear that Japanese scholars organize (mostly historians) a symposium entitled Rekishi Kyōkasho Mondai and harshly criticize the government for the kind of narratives they put in history books. However, it is also possible to witness protests in South Korea (by Koreans) or China (by Chinese) for the same reasons. The reason for the discussion of this issue in Japan is that, for so many years now, the content of the history textbooks in Japan did not bring enough self-criticism to Japan's experiences of wrong doings and pain that they caused in the historical process, did not contain enough regret for its expansionist and invasive policies towards Asian countries.

On the contrary, the history textbooks contained heroic stories and praises to the emperor. It is explained as an attempt to build a positive memory for the past through affirmation of the past policies. Chapter 4 of the study titled Collective Memory Studies in Japan, based on the intertwined relationship of history and memory, revealed the general characteristics of collective memory studies conducted in Japan. In this part, it is understood that memory studies in Japan mainly highlights the difficulties experienced after the defeat of World War II and the US invasion of Japan and studies mostly put forward victimization against USA. Finally, this traumatic situation of Japan, whose great empire image was destroyed, was explained by Vamik Volkan's chosen trauma theory. It has been revealed that the trauma of the loss of World War II in Japan still continues, and this situation is most clearly seen in the contents of the ongoing memory studies in Japan. In the Conclusion part, in addition to explaining the effects of this chosen trauma in Japan that extend to the present, alternative ideas for history education and textbooks also have been put forward so that it does not reflect on the future. 


\section{Giriş}

Tarih eğitimi, insanın geçmiş sosyal yaşamının durumunu ve tarihsel süreç içerisindeki geçişini inceleyen bir çalışma alanıdır. Tarihin konusu, insanoğlunun geçmişte deneyimlediği olaylar olduğu için günümüzden bir bakış ile doğrudan ve deneyimsel bir algılama sağlanması mümkün değildir. Varoluşun kanıtı olan tarihsel materyaller bir aracı olarak kabul edildiğinden, tarihsel materyallerin keşfi, toplanması ve doğrulanması tarihin temel araştırma yöntemleri olarak işlev görmektedir. Tarih, çok eski zamanlardan beri tanımlanmış olsa da modern bilimsel tarih olarak ifade edebileceğimiz yaklaşım, 19. yüzyılda tarihsel materyallerin iyileştirilmesi, tarih araştırmalarına yönelik yöntemlerin geliştirilmesi ve tarihi materyallerin eleştirilmesi yoluyla kurulmuştur. Tarihsel materyallerin içerikleri ve özellikleri çeşitli olup, bunlarla ilgili çeşitli sınıflandırmalar yapılsa da araştırmacılar tarafından oldukça önemsenen bakışta kabaca iki türe ayrıldığı söylenebilir: sessiz kalıntılar ve tarihi olaylara ilişkin ifadelerin yazılı olduğu raporlar. ${ }^{1}$

Bu noktada, tarihsel malzemelerin sentezlenerek anlatıya dönüştürülmesi ve tarihsel süreçteki bu tecrübelerin gelecek nesillere aktarılması birçok ülkede uzun süredir tartışlan bir konudur. Bir diğer ifade ile ülkelerin çeşitli kademelerdeki eğitim kurumlarında tarih eğitimi için kullandıkları tarih kitaplarının içerikleri, ne tür anlatılara sahip olması ya da olmaması gerektiği, çeşitli olayları ifade ederken yapılan kelime seçimlerinin ne şekilde belirlenmesi gerektiği vb. konular birçok ülkede eğitimciler başta olmak üzere toplumun entellektüellerinin gündemini işgal etmektedir. Bu tür tartışmaların, özellikle 1. Dünya Savaşı ve 2. Dünya Savaşı dönemlerinde savaşa dâhil olmuş, çevresindeki ülkeleri işgal etmiş ya da çevre ülkeler tarafından işgal edilmiş olan ülkelerde daha yoğun olduğunu söylenebilir. Japonya, bu manada bu tür tartışmaların en yoğun yaşandığı ülkelerden birisi olup Japonya' daki literatürde bu tartışmalara Tarih Ders Kitabı Sorunu (Rekishi Kyōkasho Mondai) denilmektedir.

Meiji Restorasyonu (1868) gerek Türkiye'de (Esenbel, 2015; Tuncoku, 1996), gerekse ABD ve Avrupa'daki araştırmacılar (Akamatsu, 1972; Beasley, 1995; Jansen, 2000) tarafından büyük oranda Japon Modernleşmesi'nin başlangıcı olarak tanımlanır. Bu dönemden itibaren Japonya'da sanayileşme, hukuk, eğitim vb. birçok alanda atılımların yapılmış olması, bu bakışı belirli oranda desteklemektedir. Ancak aynı zamanda Meiji Restorasyonu'nu takiben Japonya'nın bölgedeki yayılmacı politikaları ile dâhil olduğu savaşlar [1. Çin-Japon Savaşı (1894-1895), Japonya'nın Tayvan'1 İşgali (1895), Rus-Japon Savaşı (1904-1905), 1. Dünya Savaşı (1914-1918), Japonya'nın Mançurya Çıkarması (1931-1932), 2. Çin-Japon Savaş1 (1937-1945), 2. Dünya Savaşı (1941-1945) ve sonrasında gelen ABD’nin Japonya'y1 İşgali (1945-1952)] düşünüldüğünde, bu dönemin aynı zamanda Japonya için bir savaşlar tarihi olduğu da ifade edilebilir. Dolayısıyla, Asya'da çevre ülkeleri işgal ederek büyük bir imparatorluk kurmuş olan Japonya'nın, 2. Dünya Savaşı sonrası ABD işgaline maruz kalmasına kadarki süreci, gelecek nesillere ne tür tarihsel materyaller ve anlatılar ile aktaracağı, gerek Japon toplumu içerisindeki ulus kimliğin inşası, gerekse çevre ülkelerle olan ilişkileri açısından hassas bir yer teşkil etmektedir.

Tarih Ders Kitabı Sorunu (Rekishi Kyōkasho Mondai) başlığı altında toplanan bu tartışmalar, Japonya'daki araştırmacılar tarafından uzunca bir süredir ayrıntılı olarak tartışılmakta olup Çin ve Güney Kore başta olmak üzere çevre ülkeler tarafindan da yakından takip edilmektedir (Hiroshi, 2007; Kimura, 2014; Kobayashi, 1997; Nishio, 2018). Ülkemizde ise Japonya üzerine yapılan çalışmalar incelendiğinde, literatürde bu konuda yapılmış bir çalışma karşımıza çıkmamaktadır. Bu sebeple, çalışmanın üçüncü bölümünde tanıtılacak olan Tarih Ders Kitabı Sorunu (Rekishi Kyōkasho Mondai) her ne kadar çalışmanın ana konusu olmaması sebebiyle derinlemesine incelenmeyecek olsa da gerek Japonya Çalışmaları yapan araştırmacılar gerekse tarih eğitimi ya da karşılaştırmalı tarih eğitimi ile ilgilenen araştırmacılara yönelik olarak Türkiye'deki literatüre katkı sunması beklenmektedir.

Japonya'da Tarih Ders Kitabı Sorunu (Rekishi Kyōkasho Mondai) üzerine yapılan tartışmalar, aslen Japon toplumunda geçmişe yönelik mevcut olan bir bellek problemine işaret etmektedir. Connerton (1989), Halbwachs (1992) ve Nora (1996) gibi öncü araştırmacıların ortaya koyduğu eserler ile şekillenen ve 1980'lerden itibaren bilimsel bir çalışma alanı olarak kabul görmeye başlayan bellek çalışmaları, büyük oranda savaşlar ve bunlarla ilgili geçmiş olayların gelecek nesillere nasıl aktarıldığı, geçmişin ne şekilde yeniden oluşturulduğu ile ilgilenerek, tarih eğitimi ile sıkı bir ilişki içerisine girmiştir. Literatür taraması kısmında ayrıntılı olarak açıklanacak olan bu durum, Japon araştırmacılar tarafından da incelenmiş, Japonya'daki tarih eğitiminin ulus kimlik bilinci yaratma boyutunda, bir yandan kazanılan savaşlar üzerinden olumlama çabalarına, diğer yandan ise 2. Dünya Savaşı'nın bozgunundan travma boyutunda büyük oranda etkilendiğini ortaya koymuştur (Hashimoto, 2015; Nishino, 2019; Nozaki, 2008). Bu durum aynı zamanda günümüz Japonya'sındaki bellek çalışmalarını da derinden etkilemiş olup, yapılan çalışmaların büyük çoğunluğu genelde 2. Dünya Savaşı'na, özelde ise kaybedilen savaşın devam eden travmalarına odaklanmaktadır (Harootunian, 2010; Kou, 2010). Türkiye'de ise Japonya'daki tarih eğitimi ve bellek ilişkisi ile ilgili bir çalışma olmamakla birlikte, bu çalışmanın literatüre önemli bir katkı sunacağı ve ileride yapılacak olan ilgili çalışmalara bir temel oluşturabileceği söylenebilir. 
Japonya'nın içinde bulunduğu bu durum, Vamik Volkan'ın "seçilmiş travma" teorisi (2001) ile büyük uyumluluk göstermektedir. Bu teoriye göre, tarihsel süreçte belirli olaylar sonrası kitlesel olarak travmaya maruz kalan büyük gruplar, zaman içerisinde ulus kimlik inşasında bu olayları kullanarak gelecek nesillere aktarır (Volkan, 2001, ss. 1-2). Japonya'da da 2. Dünya Savaşı ve akabinde gerçekleşen ABD işgali sonrası maruz kaldığı travmanın izleri günümüzde devam etmekte olup gerek tarih eğitiminde gerekse Japonya'daki bellek çalışmalarının çalışma konularında bu durum açıkça görülmektedir. Kosova ve Yunanistan örnekleri ile "seçilmiş travma" teorisini literatüre kazandıran Vamik Volkan'ın bu bakışını Japonya ile ilişkilendirme, bu alanda yapılan öncü girişimlerden biri olarak değerlendirilebilir.

Çalışma kapsamında, betimsel analiz yöntemi kullanılarak Japonya'da tarih eğitimi ve bellek ilişkisi literatür taraması ile incelenmiştir. Ayrıca Tarih Ders Kitabı Sorunu (Rekishi Kyōkasho Mondai) tanıtılmış, günümüz bellek çalışmalarının temel eğilimleri ile "seçilmiş travma" ilişkisi ortaya konularak Japonya'nın tarih eğitimi ve toplumsal belleği arasındaki ilişkiye dair temel sorunlar tartışılmıştır. Çalışma herhangi bir eğitim kademesine odaklanmaksızın, tarih derslerindeki eğitim müfredatlarına da odaklanmaması sebebiyle tarih ders kitaplarının derinlemesine incelemesi yapılmamış olup, Japonya özelinde tarih eğitiminin toplumsal bellek ile olan ilişkisi ve mevcut sorunları literatüre kazandırmayı amaçlamıştır.

\section{Literatür Taraması ve Kuramsal Açıklamalar}

Geçmişe akademik bir bakış açısıyla yaklaşabilmek, tarih ve bellek konularını tartışabilmek için, öncelikle tarih ile tarih yazımı arasında uzun zamandır süregelen bir ikilem olması sebebiyle, tarih kavramının tartışılmasıyla başlamak yerinde olacaktır. Tarih ve tarih bilinci, çağdaş dünyada sadece akademik alanda değil, aynı zamanda gazetecilik ve kamusal tartışma alanlarında da önemli konulardır (Suzuki, 2005). Tarih kavramı özellikle 20. yüzyılın ortalarından itibaren köklü değişikliklere uğramıştır. 19. yüzyılda tarihin büyük oranda nesnel bir bilim olduğuna inanılırken, 20. yüzyılda Collingwood (1946) ve Carr (1961) başta olmak üzere çok sayıda tarihçi bu fikrin bir illüzyon olduğunu öne sürmeye başlamıştır. Bu tarihçiler arasında Carr (1961) özellikle tarihi belgelerin fetişizmi ile haklı kılınan olgu fetişizminin, o zamanlar baskın metodoloji olduğunu ve 19. yüzyıl tarih çalışmalarının günümüz tarihçilerinin bakış açısı ile değerlendirildiğinde sorunlu olduğunu öne sürmüştür. Modern tarihi ve pek çok ünlü tarihçiyi eleştiren Carr, bu görüşünü açıklamak için temel bir soru sorar: "Tarih nedir?”. Carr, bu soruya yanıt verirken tarihin geçmiş yüzyıllarda inanıldığı gibi bir nesnel gerçekler kümesi olmadığını, aksine tarihçilerin yazdığı şekliyle, o döneme dair öznel açıklamalardan oluştuğunu savmaktadır. Carr, "Gerçeklerin çoğu zaman açık olduğu söylenir. Bu tabi ki doğru değildir. Gerçekler bir tarihçi onu ortaya koymak istediği zaman ortaya çıkar. Ancak hangi gerçeklerin, hangi sıra ve hangi içerikte ortaya konulacağına tarihçi karar verir (s. 5)." sözleri ile tarihe olan eleştirel bakışını açıkça ortaya koymaktadır. Collingwood (1946) da bu görüşle benzer olarak şu ifadeleri kullanmaktadır: "Tarihe yönelik yargı koltuğunda oturan tarihçinin kendisidir ve o koltuktan kendi gücüne, zayıflığına ya da ahlaki değerlerine göre kendi zihnini ortaya koyar (ss. 218-219)."

Ayrıca, tarihin maruz kaldığı bu "keyfiliği" durumu, bazı tarihsel gerçeklerin seçilmesine veya dışlanmasına yol açar. Carr'a göre, tarihçi çalışırken, "hem gerçekler hem de hayal gücü, olayların seçimi ve sıralaması, birinin veya diğerinin karşıllklı eylemi yoluyla ince ve belki de kısmen bilinçsiz değişikliklere uğrar (s. 24)." Collingwood da benzer şekilde tarihsel düşüncenin özerkliğinin, en basit haliyle seçim çalışmasında görüldüğünü belirtmektedir (1946, s. 236). Diğer bir deyişle, bazı gerçeklere öncelik verilerek tarihsel literatüre girdiği, diğerlerinin ise ya göz ardı edildiği ya da unutulduğu söylenebilir. Bu bakış açıları, 20. yüzyılda ortaya çıkan ve tarihsel düşüncenin önemli merkezlerinden olan Anales Okulu'nun görüşleri ile de benzerlik gösterir.

Bunlara ek olarak, Carr (1961), Billig (1990), Radstone (2006) gibi alanın önde gelen araştırmacıları, tarihi günümüzde insanlar tarafından, günümüz amaçları için kullanılmak üzere yaratılmış bir yapı olarak görmektedirler. Ayrıca tarihçiler belirli bir zaman dilimi içerisinde yaşayan insanlar olarak, genellikle demokrasi, imparatorluklar, savaşlar ve devrimler gibi dönemlerine özgü kavramları kullanarak tarih yazmaktadırlar. Dolayısıyla aslında tarih, günümüzün gözünden geçmişe 1şık tutan “çağdaş tarih”tir (Carr, 1961, s. 27). Bunun sonucunda tarih, kaçınılmaz olarak, tarihçinin yaşadığı çağın özelliklerini yansıtan bir anlatı haline gelir. Bu noktada tarihçilerin geleceğe yönelik bir niyetleri olduğu unutulmamalıdır, çünkü geçmişten yararlanarak belirli amaçlarına ulaşmakla ilgilenirler.

Yukarıdaki bakış açıları ile düşünüldüğünde, dünyanın birçok yerinde olduğu gibi Japonya'da da tarih eğitiminin nasıl olması gerektiği, tarihsel anlatıların içerikleri, nelerin öne çıkarılıp nelerin unut(tur)ulmaya çalış1ldığı gibi konular önem arz etmektedir. Japon hükümeti tarih ders kitapları başta olmak üzere, çeşitli eğitim materyalleri üzerinden geçmişi olumlama, geçmişin yaralarını sarma ve buradan hareketle bir ulus kimlik bilinci oluşturmaya çalışmıştır. Nishino (2019, s. 1) Japonya'daki ortaöğretim kurumlarında kullanılan tarih kitaplarını incelediği çalışmasında, Japonya'nın homojen bir ırka sahip olması üzerinden Japon etnik ve kültürel milliyetçiliğin geliştirilmeye çalışıldığını ortaya koyarak eleştirmiş̧ir. Benzer şekilde Nozaki (2008) ve Hashimoto (2015) da Japonya'da II. Dünya Savaşı ve ABD istilası sonrası eğitimdeki sorunlara değinmiş̧ir. Her iki çalışma da savaşın kaybedilmesinin yarattığı 
travma ile birlikte bunun yaralarının sarılmaya çalışılmasının yansımaları olarak tarih ders kitaplarını işaret etmektedir. Japonya, tarih eğitimi aracılığıyla hem II. Dünya Savaşı öncesindeki zaferlerini ve bu yolda uyguladığı yayılmacı politikaları olumlamış hem de II. Dünya Savaşı yenilgisinin travmasını atlatmak ve yeni bir ulus kimlik yaratmak için girişimlerde bulunmuştur.

Tarihin göreceliliği ve Japonya'da tarih eğitimi üzerine yapılan bu tartışmalar, bizleri tarihin toplumsal bellek ile olan ilişkisini irdelemeye yönlendirir. Çünkü çoğu insan için yakın geçmiş sadece tarih değil, aynı zamanda yaşanmış bir deneyimdir (Hidaka, 2017, s. 16). Bununla birlikte, bellek kavramı üç nedenden ötürü göz ardı edilemez: Birincisi, günümüzde bile tarih, büyük otoriteler tarafından zaman zaman "bir toplumun onurlandırmayı seçtiği resmi bellekten fazlası değil (Hutton, 1993, s. 9)" olarak tanımlanmaktadır. Başka bir deyişle; tarih, günümüzde bile, genellikle sınırlı bir resmi kayıt alanı olarak düşünülmektedir. İkincisi, tarihsel anlatı yapılarının temelde geçmişin kendisinden farklı olduğu gerçeğini gözden kaçırılmamalıdır. Çünkü Ankersmit'e (1983) göre tarihçilerin epistemolojik anlatıları, bugün ve geçmiş arasındaki uyumsuzluk nedeniyle tam anlamıyla geçmişi yansıtamaz. Üçüncüsü, 1980'lerden beri hafıza çalışmalarına artan ilgiyi dikkate alarak, bu alandaki akademik birikimin bu tür çalışmalarda yeni perspektifler sunma potansiyelinin unutulmaması gerektiğidir.

Japonya'daki tarih eğitimi ile birlikte bu çalışmada ele alınmış olan toplumsal bellek çalışmaları, bizlere II. Dünya Savaşı sonrası Japonya'nın gerek eğitim dünyasında gerekse toplumsal bellek ortamında içerisinde bulunduğu sosyo-kültürel ortam hakkında önemli ipuçları sağlamaktadır. Tarih eğitimi içeriklerinde geçmişin hatalarını görmezden gelen ve geçmişi olumlayan bir yol izleyerek geçmişe dair pozitif bir bellek oluşturmaya çalışan Japonya'da, toplumsal bellek çalışmaları ABD'nin Japonya'yı işgali ve Japon halkının çektiği acılara odaklanmaktadır. Tomiyama (2006), Harutōnian (2010) ve daha birçok araştırmacının ortaya koyduğu ve ilerleyen bölümlerde daha ayrıntılı açıklanacağı üzere, Japonya için geçmişe dair toplum içerisindeki en güçlü bellek 'savaştır.'

Gerek tarih eğitiminde izlenilen strateji gerekse toplumsal bellek çalışmalarının temel eğilimleri, aslında Vamik Volkan'ın "seçilmiş travmalar" olarak ifade ettiği teorisine uygunluk göstermektedir (2001). Volkan, bu teorisinde büyük grupların karşılaştıkları belli travmaları ve verdikleri tepkileri şu şekilde açıklamıştır:

\begin{abstract}
"Kitlesel büyük grup travması ile anlatmak istediğim düşman grup tarafından bir büyük grup üzerine kasti olarak verilen yaradır. Kurban grup büyük kayıplar, utançlar, küçük düşürülme, çaresizlik ve kendini ifade edememekten dolayı acı çeker. Kitlesel travmatik grup üyeleri, kayıplarından kaynaklanan yas sürecini başarıyla geçiremezler veya utanç, küçük düşürülme ve çaresizliği tersine çeviremezler. Sosyal ya da politik alanlarda kendilerini ifade edemezler ve sonunda çaresiz öfke duygusunu içselleştirip, mazoşizmi idealize ederler veya hastalıklı sadist patlamalara eğilimli hale gelirler. Bu göstergeler toplumun genelince de paylaşılır. Kısacası kitlesel travmatik grup üyeleri, belli psikolojik görevleri başarılı bir şekilde yerine getiremezler ve bu görevleri, gelecek kuşak(lar)ın çözeceğine dair bilinçli ve bilinçsiz bir duygu paylaşımıyla gelecek kuşakların çocuklarına yansıtırlar (s. 1).”
\end{abstract}

Seçilmiş travmanın seçilmiş grubun kimlik oluşturması için önemli olduğunu belirten Volkan, bu travmaların toplumların ideolojiler geliştirmesinde de etkili olduğuna işaret etmektedir. "Düşman grubun elinde kahraman imajının, büyük grubun atalarının kitlesel travmasının temsiliyetini anlattığı (s. 1)" bu düşüncede, doğal olarak büyük grupların kurban olmaya niyetli olmaları söz konusu değildir. Fakat topluluklar geçmişi efsaneleştirmeyi seçerler ve bu meydana geldiğinde, olayın "gerçekliği" toplumsal hareketler için artık önemli değildir. "Bir olay seçilmiş travmaya dönüştüğünde, önemli olmaya başlayan, grubun travmatik olayın akli temsiliyetini taşıdığı gerçekliğidir; acı ve utancın birleştirilmiş paylaşılan duyguları yanında, nesilden nesile bu duyguları başlatan, hissedilen paylaşılmış çatışmalara karşı akli savunmalarıdır (ss. 1-2).” Bu nesilden nesile aktarım sırasında, olayın akli temsiliyeti önemli bir büyük grup işareti olarak karşımıza çıkar ve seçilmiş travma büyük grup üyelerini öncelikli olarak görünmez bir örümcek ağı gibi birbirine bağlamayla çalışır.

Vamik Volkan'ın "seçilmiş travmalar" teorisini Japonya ile örnekleme girişimi bu çalışma ile öncü bir girişim olarak değerlendirilebilir. Japonya'nın tarih eğitimi açısından düşünüldüğünde, yukarıda belirtilen "Fakat topluluklar geçmişi efsaneleştirmeyi seçerler ve bu meydana geldiğinde, olayın 'gerçekliği' toplumsal hareketler için artık önemli değildir” düşüncesi, Japonya'nın geçmişi olumlama ve pozitif bir geçmiş belleği yaratma çabaları açısından tutarlılık göstermektedir. Ancak tarih eğitimine kıyasla Volkan'ın teorisine çok daha yüksek oranda uyumluluk gösteren bölüm, Japonya'da toplumsal bellek çalışmaları bölümüdür. Dördüncü bölümde ayrıntılı olarak açıklanacağı üzere, toplumsal bellek çalışmalarının karakteristik özelliklerine bakıldığında Japonya'da II. Dünya Savaşı yenilgisinin travmaları günümüze kadar devam etmekte olup, 'savaş' günümüz Japonya'sının gerek akademik gerekse toplumsal tartışmalarının merkezinde bulunmaya devam etmektedir. 


\section{Tarih Ders Kitabı Sorunu (Rekishi Kyōkasho Mondai)}

Tarih Ders Kitabı Sorunu, genel anlamda tarih ders kitaplarının tanımlanması ve belirli bir tarih anlatısının tanınması ve yorumlanmasıyla ilgili olarak ilgili ülkelerde ortaya çıkan çeşitli problemlerle ilgilenir. Daha önce belirtildiği gibi bu konu Japonya’ya özgü olmamakla birlikte, konunun sıklıkla tartışıldığı ülkeler, II. Dünya Savaşı'nın mağlup ülkeleri olan Almanya ve Japonya'yı çevreleyen alanlarda daha yoğundur. Japonya çevresindeki bölgede, Japonya, Çin Halk Cumhuriyeti, Rusya Federasyonu ve Güney Kore arasında, tarih ders kitaplarının içerikleri ve anlatı biçimleri konusunda sıklıkla anlaşmazlıklar yaşanmaktadır. Tarih Ders Kitabı Sorunu için Çin'de Tarih Tanıma Sorunu ve Güney Kore'de Tarih Çarpıkliğı Sorunu denilmektedir.

II. Dünya Savaşı'nın bir diğer mağlup devleti olan Almanya'da da bu konu ile ilgili yoğun tartışmalar yaşanmıştır. I. Dünya Savaşı öncesinin imparatorluk Almanya'sında, ulusal tarih eğitimi kapsamında, "Almanya'nın açtığı savaşlar 'meşru savunma', başka bir ülkenin karşılık vermesi 'saldırı savaşı', Almanya'nın başka bir ülkeyi fethi 'medeniyeti ve asaleti yayma', gibi bir bakış ile anlatılar gerçekleşmiştir (Kondo, 1993, s.14)." 1925 yılı sonrası gençleri diğer milletler hakkında yanlış bilgilendirecek içeriklerin tehlikeli olduğuna yönelik uyarıları içeren toplantılar düzenlenmiş ve her ülkenin birbirine tarih kitaplarındaki içerikler ile ilgili düzeltme talepleri göndermesi konusunda anlaşmalar yapılmış olsa da (Kondo, 1993, pp.15-16), Almanya özelinde yeterli başarıya ulaşamamıştır. 1930'lu yıllardan itibaren ise Almanya'da milliyetçiliği güçlendiren tarihsel anlatıların ağırlık kazanması ile ülkeler arası iş birliği imkânsız hale gelmiş, tarih eğitimi ile ilgili tartışmalar 2. Dünya Savaşı'nın kaybedilmesi sonrası yapıcı bir biçimde ele alınmıştır. Bu doğrultuda 1950'de Almanya ile Fransa arasında, 1972'de ise Almanya ile Polonya arasında tarih ders kitapları ile ilgili düzeltmeler yapılmış, 2008'de ise Alman-Fransız ortak bir tarih ders kitabı yayımlanmıştır (ss. 60, 117).

Japonya'da da tarih kitapları ile ilgili tartışmalar II. Dünya Savaşı öncesi başlamıştır. Öncelikli olarak Japonya'nın tarih ders kitapları Çin ile sorunlar oluşturmuş, bu sorunlar daha sonra diplomatik seviyede problemlere sebep olmuştur. II. Dünya Savaşı sonrası ise, 1953 yılında ünlü Japon tarihçi Saburō Ienaga tarafından yazılan ve Japonya Millî Eğitim Bakanlığı tarafından basılan Yeni Japon Tarihi kitabı, yine bakanlık tarafindan sansüre uğramıştır. Ienaga'nın Japon savaş suçluları ve Japon hükümeti ile ilgili eleştirel ifadeleri, tarihsel gerçeklikten çok yazarın düşüncelerini içerdiği iddiası ile kitaptan çıkarılmıştır. Ienaga düşünce özgürlüğü kapsamında konu ile ilgili birçok dava açmış ve girişimleri ile Nobel Barış Ödülüne aday gösterilmişse de kitabın içeriği ile ilgili bir değişim sağlayamamıştır.

26 Haziran 1982'de Japonya'daki ders kitapları müfredatlarının baz alındığı Merkezi Sınav'da, erken Shōwa Dönemi'nde (1925-1944) Japonya'nın Kore'ye yaptığı askeri hamlelerle ilgili bir soruda, 'Japon ordusunun Huabei İstilası' olarak yer alması gereken bir soru içeriğinin, Japonya Millî Eğitim Bakanlığı'nın da resmi onayı ile 'Huabei Çıkarması' olarak değiştirilmesi, Japonya, Çin ve Güney Kore arasında diplomatik bir soruna dönüşmüştür (Shimizu, 2006, ss. 113-117). Çin'in Japonya'yı resmen protesto etmesinden kısa bir süre sonra ise bu defa Japonya Kara Kuvvetleri Sekreteri Yukiyasu Matsuno, Japonya ve Güney Kore'nin birleşmesini Güney Kore tarih kitaplarının 'Japonya'nın Güney Kore'yi işgal etmesi' olarak göstermesinin doğru olmadığını, Kore'nin o dönem içinde bulunduğu iç durum sebebiyle bu bakışın çok sağlıklı olmadığını belirtmesi Güney Kore'de büyük tepkilere sebep olmuştur (Takasaki, 1993, ss. 56-60). Sonrasında ise Japon hükümeti tarafından tansiyonu düşürücü açıklamalar yapılmış, komisyonlar kurularak ülkeler arası karşılıklı anlayışa dayalı iş birlikleri ile tarih kitaplarının yeniden ele alınacağına yönelik çeşitli taahhütler verilmiştir.

Bir süre sonra Yeni Japon Tarihi kitabı komisyonun onayı ile yayımlanmışsa da kitap içeriğinde imparatorluğa saygı, övgü içeriklerinin fazlalığı, ülkenin kuruluşu ile ilgili efsanelerin Japon milliyetçiliğini canlandırma amacı taşıması, geçmişte yapılan savaşlarla ilgili pişmanlıktan ziyade geçmişi olumlama mesajlarının fazlasıyla yer alması ülkeler arasında yeni bir krize sebep olmuştur. Konu ile ilgili çevre ülkelerin çağrıları kitap içeriğinin değiştirilmesi için yeterli olmamıştır. Sonuç olarak bu kitap 1987 yılına kadar 32 okulda sadece 8900 adet satın alınmışıı².

1990'lardan günümüze kadar bu sorun dönem dönem ülkeler arası diplomatik krizlere sebep olmaya ve araştırmacılar tarafından da tartışılmaya devam etmektedir. Geçmişte yapılan savaşların olumlamalarının yapıldığı, gelecek nesillere yönelik milliyetçiliğin yeniden inşasına yönelik ders içeriklerinin eleştirileri (Fuwa, 2001), Japonya'nın çevre ülkeleri işgal ettiği dönemlerde işlediği savaş suçlarının sorumluluğunu alması gerektiği ve tarih ders kitaplarının bu anlatılara sahip olması gerektiği (Abe vd., 2001) gibi birçok çalışma mevcuttur. Ancak tüm gerginliklere, diplomatik krizlere ve araştırmacıların uyarılarına rağmen Japonya'nın tarih ders kitapları içerik açısından Japonya'nın geçmişteki savaş tecrübeleri ile ilgili yeterli oranda özeleştiri bulundurmamakta, yer yer atalarını överek milliyetçiliği körüklemekte ve hatta II. Dünya Savaşı ile ilgili olarak savaşı toptan ele alan bir yaklaşım yerine ABD'nin ülkelerine uyguladığı orantısız güce (atom bombasına) odaklanarak kendi mağduriyetlerine ağırlık vermeye devam etmektedir.

\footnotetext{
2 Japonya'da eğitim kurumları ders kitabı olarak Milli Eğitim Bakanlığı tarafından onaylanan kitaplar arasından seçim yapma konusunda özgürdür.
} 


\section{Japonya'da Toplumsal Bellek Çalışmaları}

Japonya'da II. Dünya Savaşı'nın travmatik izleri, tarih kitaplarından daha büyük oranda toplumsal bellek çalışmalarında kendisini göstermektedir. Jacques Le Goff $(1999$, s. 2), son yıllarda tarih ve belleğin hemen hemen aynı kabul edildiğini, hatta zaman zaman belleğin tarihten daha fazla önemsendiğini belirtmektedir. Bu açıdan toplumsal bellekle alakalı Japonya'da en açık şekilde önemsenen konunun II. Dünya Savaşı olduğu söylenebilir. Yapılan çalışmalada her şeyden önce savaş sonrası (sengo) kelimesi göze çarpmaktadır. Kou Youngran (2010), çalışmasında savaş sonrası kelimesi ile ifade edilen boşluğun doldurulduğu ana odaklanır ve bu anı tarihsel bellekte bir çatlağın göründüğü ve hafızanın yeniden düzenlendiği an olarak tanımlar. Kou düşüncelerini şu şekilde ifade etmektedir:

“15 Ağustos 1945'i dönüm noktası olarak kabul eden kelime, 'Savaş Sonrası'. Önyargılı ve tek taraflı oluşturulmuş olan bu kelime ile ortaya konulan bellek, ABD ile yapılan savaşa, hatta sadece Japonya'nın savaşı kaybetmesine odaklanmaktan öteye gitmemektedir.” (s. 10)

Kou, savaş sonrası kelimesinin Japonya'nın Asya'ya yönelik yayılmacı politikalar yürüttüğü, savaşlar kazanarak sömürgeler oluşturduğu dönemleri kapsamamasını eleştirerek bu durumun Japonya'nın bellek çalışmalarının özelliklerinden biri olduğunu belirtmektedir. Ayrıca Pierre Nora'nın Hafiza Mekânları (2003) kitabının Japonca çevirisini yapan Minoru Tanigawa'ya göre “Japonya'da bellek kavramını anlamak için her şeyden önce 1990'larda popülerleşen 'savaş belleği' kavramının anlaşılması gerekir (s. 7)." Tanigawa da Japonya' da bellek çalışmalarının 'savaş belleği’ ekseninde tartışıldığını ifade etmektedir.

Tomiyama (2006), belleğe giden aşamaları deneyim, tanıklık, ve bellek olarak tanımlar. Bu üçü arasındaki ilerlemenin zamana bağlı ve kronolojik olarak ilerlediğini ileri sürer (s. 4). Tomiyama'ya göre bu 'deneyim', 'tanıklık' ve 'bellek' kavramları, Japonya'nın savaş sonrası kavramı ile şu şekilde ilişkilendirilmektedir: Başlangıçta II. Dünya Savaşı'nı tecrübe eden insanlar, savaş sonrası hayatta kalanlar ile karşı1ıklı tecrübelerini paylaşırlar ve bu tecrübe dönemini ifade eder (s. 4). 1970'li yıllara gelindiğinde toplumda savaş tecrübesi olanlar ve olmayanlar bir aradadır ve savaşı tecrübe edinenler etmeyenlere yaşadıklarını aktarıllar, yeni gelen nesil bu insanların tecrübelerine tanıklık eder. Bu şekilde tanıklık dönemi başlar (s. 4). 1990'lı yıllardan itibaren ise savaşı tecrübe etmemiş insanlar çoğunluktadır ve artık kendilerine kuşaktan kuşağa anlatılan savaş anlatıları ana hikâyeyi oluşturmaya başlamıştır. Bu dönem de bellek dönemini ifade eder (s. 4). Dolayısıyla Tomiyama'ya göre Japonya için 1950’ler tecrübe, 1970 sonrası tanıklık, 1990 sonrası ise bellek dönemini temsil eder. Günümüz Japonya'sının II. Dünya Savaşı belleğine bu derece yoğunlaşıyor olmasında Tomiyama'nın bu görüşü ile bağlantı kurmak da mümkün olabilir.

Buna ek olarak, Harutōnian (2010) da Japonya'daki bellek çalışmaları ile ilgili tespitlerde bulunmaktadır. Harutōnian öncelikle 1990'lı yıllardan itibaren Japonya'da ABD ile savaşın sona ermesinin 50. yıldönümü vesilesi ile yayımlanan kitap ve makalelere dikkat çekmiş, bu yayınların içeriklerini "savaşın yenilgisinden bugüne kadar geçen yarım asırda Japonya'nın kat ettiği yolun anlamlandırılması çabası (s. 123)" olarak tanımlamışıtır. Harutōnian ayrıca Japonya' da geçmişe yönelik belleğe ilişkin ilginin yükselişte olduğunu belirtmekle birlikte, bu ilginin temel eğilimlerini şu sözlerle eleştirmiştir:

“Japonya'da bellek çalışmaları, Asya ülkelerinde soykırıma, yıkıma ve yenilgiye yol açan savaşın anlamını anlamaya çalışmaktan ziyade, savaşta kaybedilenler ile savaş sonrasını yaşamış olan Japon halkı arasındaki ilişkiyi konu alıyor." (s. 123)

Buraya kadar örneklerle ortaya koyduğumuz üzere, Japonya'da toplumsal bellek çalışmaları büyük oranda II. Dünya Savaşı'na odaklanmış durumdadır. Başka bir ifadeyle, Nora'nın "şimdiki zamanın içinde var olan geçmiş (s. 5)" olarak belirttiği kavram, Japonya örneğinde savaş kelimesine karşılık gelmekte olup, Japonya'nın toplumsal bellek çalışmaları da bu tema etrafında toplanmış durumdadır. Bu yaklaşımın Japonya'daki bellek araştırmalarının kapsamını önemli ölçüde daralttığı söylenebilir ancak bu eğilim Japonya'ya özgü de değildir. Almanya ve Fransa'da geçmiş savaşlar üzerine yapılan hafıza araştırmalarında da benzer özellikler görülebilir. Ancak Japonya'yı diğer ülkelerden ayıran en önemli nokta, çoğunluğu Japon olan bellek araştırmacılarının Meiji Restorasyonu ile başlayarak II. Dünya Savaşı'na ve sonrasında gelen atom bombası felaketine giden yolda Japonya'nın geçmiş tecrübelerini gözardı etmesi, özeleştiriden uzak bir bakış açısı ile sadece II. Dünya Savaşı'nda ABD karşısında uğradığı malubiyete ve sonrasında Japon toplumunun yaşadığı zorluklara odaklanıyor olmasıdır.

Japonya'ya özgü olarak ifade edilebilecek olan bu özellik, Vamik Volkan'ın "seçilmiş travmalar" teorisi ile önemli ölçüde uyuşmaktadır. Bu teori üzerinden değerlendirmek gerekirse Japonya'nın içinde bulunduğu bu durum kitlesel büyük grup travmasıdır. Düşman grup (ABD) tarafından büyük grup (Japonya) üzerinde II. Dünya Savaşı ile büyük bir yara açılmış, bu durum o döneme kadar Asya'nın en güçlü imparatorluğu olan Japonya üzerinde büyük bir psikolojik kırılmaya sebep olmuştur. Kurban grup olarak Japonya, büyük kayıplar, utançlar, küçük düşürülme, çaresizlik ve kendini ifade edememekten dolayı acılar çekmiş, kitlesel travmatik grup üyeleri, kayıplardan kaynaklanan yas 
sürecini başarıyla geçirememişlerdir. Kısacası, kitlesel travmatik grup üyeleri, belli psikolojik görevleri başarılı bir şekilde yerine getirememiş ve bu görevleri, gelecek kuşakların çözeceğine dair bilinçli veya bilinçsiz bir duygu paylaşımıyla gelecek kuşakların çocuklarına yansıtmışlardır. Japonya özelinde bu "seçilmiş travma" durumu bellek çalışmaları ile vucüt bulmuş olup, ABD karşısında tecrübe edinilmiş olan yenilgi, bellek çalışmaları aracılığıyla bir savaş mağduriyeti olarak yeni nesillere sunulmakta ve yeniden oluşturulan bu bellek üzerinden ulus kimlik bilinci inşa edilmeye çalışılmaktadır.

\section{Değerlendirme}

Tarihin nasıl, hangi materyallerle, hangi anlatılarla ve ne şekilde öğretilmesi gerektiği, birçok ülkede yoğun olarak tartışılan alanlardan birisidir. Bu tartışmalar, I. Dünya Savaşı ve II. Dünya Savaşı'na müdahil olmuş ve özellikle de savaşın kaybedeni olmuş olan ülkelerde daha yoğun şekilde yaşanmakta olup, çalışmada incelediğimiz Japonya, bu ülkelerin başında gelmektedir. Tarihsel malzemelerin sentezlenerek anlatıya dönüştürülmesi ve tarihsel süreçteki bu tecrübelerin tarih ders kitapları aracılığıyla gelecek nesillere aktarılması, Japonya'da çeşitli sorunları bünyesinde barındırmaktadır. Tarih Ders Kitabı Sorunu olarak ifade edilen bu durum gerek Japonya içerisinde gerekse çevre ülkelerde çeşitli tartışma ve gerilimlere sebep olmaktadır. Bunun sebebi Japonya'nın tarih eğitimi için kullandığı ders kitaplarında Meiji Restorasyonu'ndan II. Dünya Savaşına ve akabinde gelen ABD istilasına kadarki süreçte Asya kıtasındaki militarist ve yayılmacı politikalarının yeteri kadar özeleştirel bir çerçeveden sunulmaması, hatta savaş olumlamalarına ve yer yer imparator övgülerine yer veriyor olmasıdır. Ayrıca ABD'nin atom bombası atması ile sonuçlanan II. Dünya Savaşı'na yönelik olarak da aynı perspektife sahip ders içerikleri verilmekte olup, atom bombası ve işgal dönemi ile gelen mağduriyet süreci öne çıkarılmakta, bu çerçeveden bir ulus kimlik bilinci oluşturulmaya çalışılmaktadır.

Japonya'nın gelecek nesillere yönelik yaratmaya çalıştığı bu ulus kimlik bilinci, "seçilmiş travma" olarak seçmiş olduğu II. Dünya Savaşı yenilgisi ve işgal dönemine yönelik gerçekleştirilen toplumsal bellek çalışmalarında daha net şekilde karşımıza çıkmaktadır. Japonya'nın bellek çalışmaları büyük oranda "savaş" ile ilişkilendirilmiş olup, II. Dünya Savaşı üzerine yapılan çalışmalar çoğunluğu oluşturmaktadır. Ayrıca, çoğunluğu Japon araştırmacılar tarafından gerçekleştirilen bu çalışmalar, Japonya'nın militaristleşmesine ya da yayılmacı politikalarına yönelik bir özeleştiri barındırmaksızın, savaşın kaybedilmesi ve ABD işgali ile ne kadar derin acılar yaşadıklarına odaklanmaktadır. Bir diğer ifade ile Vamik Volkan'ın "seçilmiş travmalar” teorisi üzerinden düşünüldüğünde, II. Dünya Savaşı yenilgisinin Japonya'nın "seçilmiş travması" olarak karşımıza çıktığı, savaş sonrası büyük imparatorluk imajının kaybedildiği ve yenilginin psikolojik travmasının günümüze kadar devam ettiği, Japonya'da yapılan toplumsal bellek çalışmaları incelendiğinde açıkça görülmüştür.

Tarihin sadece geçmişle ilgili olmadığı, geçmişi bugüne, bugünü ise geleceğe bağlayan bir işlev gösterdiği unutulmamalıdır. Bu bağlamda Japonya ve ona benzer geçmiş tecrübelere sahip olan ülkelerin, tarih ve bellek arasındaki ilişkiyi göz ardı etmeden, gerçekçi, duyarlı ve şeffaf bir şekilde tarih eğitim programları hazırlamaları gereklidir. Gelecek kuşakların geçmişten gelen birtakım travmalara takılıp kalmaksızın, sağlıklı ve gerçekçi değerlendirmelerde bulunabilmesi, tarihten doğru dersleri çıkartabilmesi ve geleceğe yönelebilmesi ancak bu şekilde sağlanabilir.

Yazar çalışmanın tamamını gerçekleştirmiştir.

\section{Araştırmacıların Katkı Oranı}

\section{Destek ve Teşekkür}

Yazar çalışma için herhangi bir finansal destek almamıştır.

\section{Çıkar Çatışması}

Yazar çalışmada herhangi bir çıkar çatışmasının bulunmadığını beyan etmiştir. 


\section{Kaynakça / References}

Abe, S., Okano, Y., Kōno, Y. (2001). Shinryakusensō Shokuminchi Shihai no Hansei to Rekishikyōkashomondai [Fetih savaşları, sömürge yönetimine yansımaları ve tarih ders kitabı sorunları]. Gikai to Jichitai, (38), 87-93.

Akamatsu, P. (1972). Meiji 1868: Revolution and Counter-Revolution in Japan. New York: Harper \& Row.

Ankersmith, F. R. (1989). Historiography and postmodernism. History and Theory, 27(2), 137-153.

Beasley, W. G. (1995). The rise of Modern Japan: Political, economic and social change since 1850. New York: St. Martin's Press.

Billig, M. (1990). Collective memory, ideology and the British Royal Family. In D. Middleton \& D. Edwards (Eds.), Collective remembering (pp. 60-80). London: Sage.

Carr, E. H. (1961). What is history? London: Palgrave.

Collingwood, R. G. (1946). The idea of history. Oxford: Oxford University Press.

Connerton, P. (1989). How societies remember: Themes in the social sciences. Cambridge: Cambridge University Press.

Esenbel, S. (2015). Japon modernleşmesi ve Osmanlı: Japonya’nın Türk Dünyası ve islam politikaları. İstanbul: İletişim Yayıncılık.

Fuwa, T. (2001). 'Nihon wa Tadashī Sensō o Yatta' - Kodomotachi ni kō Omoikomaseru Kyōiku ga Yurusareru ka [“Japonya Savaşmakta Haklıydı!’ çocukları böyle düşündüren eğitim kabul edilebilir mi?]. Zenei, (742), 39-49.

Jakku, R. G. (1999). Rekishi to Kioku [Tarih ve bellek] (Çev. K. Tachikawa). Japan: Hōseidaigaku Shuppankyoku.

Jansen, M. B. (2000). The making of modern Japan. Cambridge, MA: Harvard University Press.

Halbwachs, M. (1992). On collective memory: Heritage of sociology series (Trans. A. C. Lewis.). Chicago, IL: University of Chicago Press.

Harutōnian, H. (2010). Rekishi to Kioku no Kōsō - Sengonihon no Genzai. [Tarih ve bellek arasındaki çatışma - Savaş sonrası Japonya'nın 'bugünü']. Japan: Misuzushobō.

Hashimoto, A. (2015). The long defeat: Cultural trauma, memory, and identity in Japan. Oxford: Oxford University Press.

Hidaka, K. (2017). Japanese media at the beginning of the 21st century. London: Routledge.

Hiroshi, M. (2007). Rekishikyōkashomondai (Rīdingusu Nihon no Kyōiku to Shakai - Dai 6-kan) [Tarih ders kitabı sorunu - Japon toplumu ve eğitimi okumalarl 6]. Japan: Nihon Tosho Sentā.

Hodgkin, K., Radstone, S. (2006). Memory, history, nation. London: Transaction Publishers.

Hutton, P. H. (1993). History as an art of memory. Lebonan, NH: University Press of New England.

Kimura, K. (2014). Nikkan Rekishi Ninshiki Mondai to wa nani ka? [Japonya - Kore tarih anlatısl problemi nedir?]. Japan: Mineruvu Ashobō.

Kobayashi, Y. (1997). Shin Gōmanizumu Sengen 4 - Rekishikyōkashomondai [Yeni Gomanizm Bildirgesi 4 - Tarih ders kitabı sorunu]. Japan: Shōgakukan.

Kondo, T. (1993). Doitsu Gendaishi to Kokusai Kyōkasho Kaizen - Posuto Kokumin Kokka no Rekishiishiki [Çăgdaş Alman Tarihi ve uluslararası ders kitaplarının gelişimi - Ulus-devlet sonrası tarihsel farkındalık]. Japan: Nagoyadaigakushuppankai.

Kō, Y. (2010). Sengo to iu İdeorogi - Rekishi / Kioku / Bunka ['Savaşsonrası' denilen ideoloji - Tarih / bellek / kültür]. Japan: Fujiwara Shoten.

Nishino, R. (2019). The Palgrave Handbook of Ethnicity - Cultural identity and textbooks in Japan: Japanese ethnic and cultural nationalism in middle-school history textbooks (pp. 1-17). Singapore: Springer.

Nishio, K. (2018). Rekishikyōkashomondai [Tarih ders kitabı sorunu]. Japan: Kokushokankōkai. 
Topaçoğlu

Nora, P. (1996). Realms of memory: Rethinking the French past, Vol. 1 - Conflicts and divisions. New York, NY: Columbia University Press.

Nora, P. (2003). Kioku no Ba - Furansu Kokumin Ishiki no Bunka - Shakaishi [Hafiza mekanları - Fransız ulusal bilinç kültürü / sosyal tarih] (Çev. M. Tanigawa, Minoru). Japan: Iwanamishoten.

Nozaki, Y. (2008). War memory, nationalism and education in Postwar Japan, 1945-2007: The Japanese history textbook controversy and Ienaga Saburo's court challenges. London: Routledge.

Shimizu, Y. (2006). Chūgoku wa naze Hannichi ni natta ka? [Çin neden Japonya karşıtı oldu?]. Japan: Bunshun shinsho.

Suzuki, M. T. (2005). The past within US: Media, memory, history. London: Verso.

Takasaki, S. (1993). Hannichi Kanjō - Kankoku, Kansenjin to Nihonjin [Japon karşıtll̆̆gl - Koreliler ve Japonlar]. Japan: Kōdanshagendaishinsho.

Tomiyama, I. (2006). Kioku ga Katarihajimeru [Bellek konuşmaya başlar]. Tokyo: Tōkyodaigakushuppan.

Tunjoku, A. M. (1996). Nihon to Toruko no Kindaika - Gaikokujin no Yakuwari [Türk - Japon Modernleşmesi - Yabancıların rolü]. Japan: Saimaru Shuppankai.

Vamik, D. V. (2001). Transgenerational transmissions and chosen traumas: An aspect of large-group identity. Group Analysis, 34(1), 79-97. 